\title{
Characterising the variability of transit time distributions and young water fractions in a karst catchment using flux tracking
}

\author{
Zhicai Zhang ${ }^{1}$, Xi Chen ${ }^{2}$, Qin-bo Cheng ${ }^{1}$, and Chris Soulsby ${ }^{3}$ \\ ${ }^{1}$ Hohai University \\ ${ }^{2}$ Tianjin University \\ ${ }^{3}$ University of Aberdeen
}

May 5, 2020

\begin{abstract}
Water transit time and young water fraction are important metrics for characterizing catchment hydrologic function and understanding solute transport. Hydrological and biogeochemical processes in karst environments are strongly controlled by heterogenous fracture-conduit networks. Quantifying the spatio-temporal variability of water transit time and young water fractions in such heterogeneous hydrogeological systems is fundamental linking discharge and water quality dynamics in the karst critical zone. We used a tracer-aided hydrological model to track the fluxes of water parcels that entered a karst catchment as rainfall, time-stamping each hour of rain input individually. Using this approach, the variability of transit times and water age distributions were estimated in the main landscape units in the karst catchment of Chenqi in Guizhou Province, Southwest China. The estimated mean young water (i.e $<\sim 2$ months old) fractions were $0.39,0.31$ and 0.10 for output fluxes from the hillslope unit, catchment outlet and slow flow reservoirs (matrix and small fractures), respectively. Marked seasonal variability in sources of runoff generation and associated hydrological connectivity between different conceptual stores were the main drivers of young water fraction dynamics in each landscape unit. The water age and travel time distributions were strongly influenced by the water storage dynamics reflecting catchment wetness conditions. Even though the contribution of young water to runoff was greater, the older water turnover was generally accelerated at moderately high flows during wet season.
\end{abstract}

\section{Introduction}

Transit time distributions (TTD) are a fundamental characteristics of catchment hydrological function, which can indicate the dynamics of water movement and solute transport in watersheds (Kirchner et al., 2000; McDonnell and Beven, 2014). The TTD gives conceptual, integrated understanding of the nature of flow paths that transform precipitation inputs (e.g. rainfall, snowmelt) to runoff at the catchment outlet, and their associated temporal dynamics. Mean transit time (MTT) defines the average travel time between water entering and leaving a catchment, which provides indication of water movement under different meteorological condition and for contrasting watershed characteristics (Hrachowitz et al., 2009). The MTT can be determined from the TTD; however, estimates of MTT can often be biased, especially for spatially heterogeneous catchments with heavy tailing of old water distributions (Kirchner, 2016a; Seeger and Weiler, 2014). Consequently, the young water fraction $\left(\mathrm{F}_{\mathrm{yw}}\right)$, i.e. the average fraction of stream flow that is younger than a specified threshold age (typically between two and three months), has recently been proposed as a more reliable and stable descriptive metric of the TTD for spatially heterogenous and non-stationary conditions by Kirchner $(2016 \mathrm{a}, \mathrm{b})$. A distinct advantage of this approach is that the estimation of $\mathrm{F}_{\mathrm{yw}}$ does not need to assume a particular shape of the underlying TTD.

Currently, there are two main broad approaches for water transit time and age estimation: data-driven and model-driven approaches (McCallum et al., 2014). In the former approach, TTDs are estimated by fitting 
conservative tracer concentrations using inverse lumped parameter models, and then MTTs are determined from corresponding TTDs (McGuire and McDonnell, 2006; Peralta-Tapia et al., 2016). In the latter approach, the water transit times and age can be tracked directly by a tracer-aided hydrological model with calibrated parameters related to flow and tracer simulations (Hrachowitz et al., 2013; Soulsby et al., 2015; Remondi et al., 2018). Although it is difficult for data-driven approaches to constrain the spatial variation of flow transit times and water age distributions within a catchment, the influence of climate and landscape properties can also be assessed by catchment inter-comparison of the MTT and $\mathrm{F}_{\mathrm{yw}}$ determined by the data-driven method. For example, comparison of MTT determined by data-driven methods across a range of environmental gradients catchments, Hrachowitz et al. (2009, 2010) and Heidbüchel et al. (2013) helped disentangle the relative influence of controls due to meteorological conditions and watershed characteristics (e.g. drainage density, topographic wetness index, soil cover and storage capacity, antecedent moisture conditions and precipitation event characteristics) on stream water ages. Similarly, the relationships between $\mathrm{F}_{\mathrm{yw}}$ and terrain, soil, and land-use indices, as well as the precipitation characteristics have been examined in 22 Swiss catchments (von Freyberg et al., 2018). In addition, Jasechko et al. (2016) calculated the $\mathrm{F}_{\mathrm{yw}}$ of streamflow of 254 relatively large catchments around the world, and they found there is no significant correlation between $\mathrm{F}_{\mathrm{yw}}$ and annual rainfall, but there is an inverse correlation with the average topographic gradients inferring deeper vertical infiltration in steeper catchments.

Alternatively, where transit times and water ages are tracked using tracer-aided hydrological models (e.g. Benettin et al., 2015a; Hrachowitz et al., 2013, 2016; McMillan et al., 2012), although such models are usually conceptual, they have stronger skill in capturing the spatio-temporal variability of catchment transit times and water age due to non-stationarity conditions and spatial heterogeneity. These approaches have contributed to the enhanced understanding of spatial variation in runoff generation and solute transport processes and have shown how this influences the dynamics of transit times and water ages at the catchment scale (Birkel et al., 2012; Soulsby et al., 2015). Process-based models, with more complex structures and parameterisation, can provide more physically-based descriptions of catchment hydrological processes, and can give more integrated understanding of tracking flow transit times and water ages and analysing how hydrometeorological conditions and spatial heterogeneity may affect the TTD and $\mathrm{F}_{\mathrm{yw}}$ (Kuppel et al., 2018a; Remondi et al., 2018). However, the high parameterisation of such models can increase uncertainty, unless detailed data on watershed states (soil moisture storage, groundwater levels etc.) and hydroclimatic inputs are available for multi-criteria model calibration, which limit the application of this method to more intensively instrument catchments (Kuppel et al., 2018b).

As both climate and landscape characteristics interact to determine transit times and water ages, understanding how catchment morphological properties and external meteorological forcing control TTDs and water age remains challenging. Most studies are site specific and focused in humid temperate catchments, so generalization to different geographical regions is rarely possible (Burt and McDonnell, 2015; Birkel and Soulsby, 2015; Maxwell et al., 2016). For example, karst regions cover $12 \%$ of the Earth's surface and are the main source of drinking water to over $25 \%$ of the world's population (Ford and Williams, 2013). However, due to the high spatial variability of the hydrodynamic properties and hydrological connectivity of the karst critical zone, the TTD and water age of catchment water fluxes have significant spatial and temporal variability (Zhang et al., 2019). Unfortunately, there is relatively little research on this issue (see Chen et al., 2018).

Because of the unique nature of karst geology and geomorphology, and characteristic features such as vertical shafts, caves and sinkholes, the spatial heterogeneity of drainage systems is high. The complex underground mixed-flow systems in karst aquifers include low velocity flows within the matrix and small fractures, and high velocity flow within large fractures and conduits (White, 2007; Worthington, 2009), which lead to a highly dynamic spatio-temporal variability of hydrological processes (Bakalowicz, 2005; Ford and Williams, 2013; Hartmann et al., 2014a). Hu et al. (2015) estimated the mean residence time of water at a karst epikarst spring with contributing area less than $1 \mathrm{~km}^{2}$ in South China, based on detailed observations of hydrogen and oxygen isotopes. In their study, the MTT in epikarst spring was longer than one year, indicating that the epikarst had poor connectivity and high water retention, and could thus maintain continuous contributions to surface water. Hartmann et al., (2014b) simulated the time-variant transit time distributions of an Austrian 
karst system using a semi-distributed model, and showed that the variation in transit time in the karst area is very large, and can range from days to several years. However, these studies considered entire karst basins, and there is a need to understand the TTD and $\mathrm{F}_{\mathrm{yw}}$ of water fluxes in different geomorphological units (e.g. hillslope and depression) or different mediums (e.g. dual flows in within the matrix and conduits) within karst landscapes, which are crucial for the understanding the interactions of hydrological processes and water quality in drainage waters.

The aim of this study is to address this research gap in the Chenqi catchment in SW China. The specific objectives are: (1) to use the output from a tracer-aided model to quantify the young water fraction (defined according to Kirchner, 2016a, b) of water storages in, and fluxes between, the main compartments of a complex karst landscape; (2) to examine the seasonal inter-relationships between storage and the young water fraction of the dominant water fluxes as hydrological connectivity changed; and (3) to assess the time variance of the water age and travel time distributions between the main seasons using flux tracking.

\section{Site and Methodology}

\section{Study catchment}

Chenqi catchment is located in the Puding Karst Ecohydrological Observation Station of Guizhou Province, southwest China, and has an area of $1.25 \mathrm{~km}^{2}$ (Fig. 1). It is a typical cockpit karst landscape, with surrounding conical hills separated by star-shaped valleys (Zhang et al., 2011; Chen et al., 2018). The catchment, which is drained by a single underground channel/conduit, can be divided into two units: depression areas with low-elevation $(<1340 \mathrm{~m})$ and steeper hillslopes with high elevation ranging from 1340 to $1500 \mathrm{~m}$. The site has a subtropical wet monsoon climate with mean annual temperature of $20.1{ }^{\circ} \mathrm{C}$, and the highest temperatures in July and lowest in January. The annual precipitation is $1,140 \mathrm{~mm}$, with a distinct wet summer season from May to September and a dry winter season from October to April. The average monthly humidity ranges from 74 to $78 \%$.

Geological strata in the study basin include dolostone, thick and thin limestone, marl and Quaternary soil. Limestone formations 150-200 m thick lie above an impervious marl formation, which allows precipitation to recharge perched groundwater on the marl that discharges in the lower areas (mostly as hillslope springs). On hillslopes, Quaternary soils developed on carbonate rocks are very thin, and the average soil thickness is less than $30 \mathrm{~cm}$. Some limestone fragments are mixed in with the soils, and the rock outcrop area is $10-30 \%$. The vegetation characteristics include deciduous broad-leaved forest at the top and middle of the hillslope and crops (including rice paddies) on the depression where soils are also thicker.

At Chenqi, discharge of a hillslope spring (HS) located at the foot of the eastern steep hillslope and the underground channel at the catchment outlet were measured (Fig. 1). An automatic weather station was established on the upper hillslope to record precipitation, air temperature, wind, radiation, air humidity and air pressure. Additionally, precipitation, hillslope spring discharge and catchment outlet flows were sampled daily for hydrogen and oxygen isotopes analysis. These hydrometric and isotopic data were used to analyze the seasonal cycles, and short-term dynamics of stream water and precipitation isotopes and aid model calibration.

\section{Young water fraction}

The young water fraction $\left(\mathrm{F}_{\mathrm{yw}}\right)$ is the fraction of water with transit times between zero and a young water threshold $\left(t_{y}\right)$ is described by the following:

$F_{\mathrm{yw}}=\int_{0}^{t_{y}} h(\tau) d \tau(1)$

where $h(\tau)$ is the flow model of the hydrological system based on the distribution of water fluxes in the catchment.

The sine-wave approach for the young water fraction expresses the seasonal cycles of stream water and precipitation isotopes developed by Kirchner (2016a). The seasonal isotope cycles in precipitation and stream water can be described by the following: 
$C_{p}(t)=A_{p} \sin \left(2 \pi f t-\varphi_{p}\right)+k_{p}(2)$

$C_{s}(t)=A_{s} \sin \left(2 \pi f t-\varphi_{s}\right)+k_{s}(3)$

where $A$ is the amplitude (the seasonal cycle (in radians, with $2 \pi$ rad equalling 1 year), $t$ is the time (decimal years), $f$ is the frequency $\left(\mathrm{yr}^{-1}\right)$ and $k$ (vertical offset of the isotope signal. The subscripts $p$ and $s$ represent precipitation and stream water, respectively. The amplitudes $A_{s}$ and $A_{p}$ of the seasonal isotope cycles in Eqs. (2) and (3) can be estimated by using multiple linear regression to obtain the coefficients $a$ and $b$ in the following:

$C_{p}(t)=a_{p} \cos (2 \pi f t)+b_{p} \sin (2 \pi f t)+k_{p}(4)$

$C_{s}(t)=a_{s} \cos (2 \pi f t)+b_{s} \sin (2 \pi f t)+k_{s}(5)$

The amplitudes $A_{S}$ and $A_{P}$ are then determined by the following:

$A_{p}=\sqrt{a_{p}^{2}+b_{p}^{2}}(6)$

$A_{s}=\sqrt{a_{s}^{2}+b_{s}^{2}}(7)$

Following Kirchner (2016a), we calculate $\mathrm{F}_{\mathrm{yw}}$ as the amplitude ratio $A_{s} / A_{p}$, for the hillslope unit and catchment. And the threshold age for $\mathrm{F}_{\mathrm{yw}}\left(t_{y}\right.$ in Eq. (1)) is 0.189 years (69 days), which equals the threshold age for seasonal cycles convolved with an exponential TTD. This method of quantifying the $\mathrm{F}_{\mathrm{yw}}$ can be much more reliable than using the MTT, particularly in heterogeneous and nonstationary catchments (Kirchner, 2016a, b).

According to the method, we fitted sine waves to the daily precipitation and streamflow isotope data, from November 2016 to October 2017, at a hillslope spring and catchment outlet (in Fig.1) using iteratively reweighted least squares (IRLS), with rainfall/discharge-weighting. The statistical analysis was completed using the R language (R Core Team, 2017), and the significance level of the hypothesis test was 0.05.

\section{Tracer-aided model and water dynamics tracking}

In an earlier paper (Zhang et al., 2019), we describe in detail the development of a tracer-aided hydrological model for the catchment that disaggregates cockpit karst terrain into the two dominant landscape units of hillslopes and depressions. Briefly, the water and tracer movement were simulated using a two-reservoir model that conceptualizes the dual-flow system. The low permeability "slow flow" reservoir represents the fractured matrix blocks of the aquifer, and the highly permeable "fast flow" reservoir represents the large conduits (Fig.2). And the outlet of the fast flow reservoir is the catchment outlet (Fig.2). The water balance for each of the three reservoirs (hillslope unit, fast flow and slow flow reservoirs in depression) in the catchment is expressed as:

$\frac{d V_{n}}{\mathrm{dt}}=\sum_{i=1}^{k} Q_{n, \text { in }, i}-\sum_{j=1}^{m} Q_{n, \text { out }, j}(8)$

where $V$ is storage with the subscript of $n=h, f, s$, representing hillslope unit, fast flow and slow flow reservoirs, respectively. $Q_{n}$,in and $Q_{n, \text { out }}$ are the flow discharges that enter and exit the $n$th reservoir. The model tracks and simulates the isotope ratios for each reservoir separately, and the complete mixing of the isotope ratios is assumed for the slow and fast flow reservoirs:

$\frac{d i_{s}\left(V_{s}\right)}{\mathrm{dt}}=\sum_{i=1}^{k} i_{s, \text { in }} Q_{s, \text { in }, i}-\sum_{j=1}^{m} i_{s, \text { out }} Q_{s, \text { out }, j}(9)$

$\frac{d i_{f}\left(V_{f}\right)}{\mathrm{dt}}=\sum_{i=1}^{k} i_{f, \text { in }} Q_{f, \text { in }, i}-\sum_{j=1}^{m} i_{f, \text { out }} Q_{f, \text { out }, j}(10)$

where $i$ is the $\delta \mathrm{D}$ signature of the storage components (partial mixing (e.g. the upper active storage mixing with the lower passive storage in Fig.2 since the upper rock fractures/conduits reduce exponentially along the hillslope profile) is assumed for the hillslope according to:

$\frac{d i_{h}\left(V_{h}\right)}{\mathrm{dt}}=\sum_{i=1}^{k} i_{h, \text { in }} Q_{h, \text { in }, i}-\sum_{j=1}^{m} i_{h, \text { out }} Q_{h, \text { out }, j}-i_{h} Q_{e}+i_{\text {pas }} Q_{e}(11)$ 
$\frac{d i_{\mathrm{pas}}\left(V_{\mathrm{pas}}\right)}{\mathrm{dt}}=i_{\mathrm{pas}} Q_{e}-i_{h} Q_{e}(12)$

where the additional volumes $V_{\text {pas }}$ is the storage of passive reservoir in hillslope which is available to determine isotope storage, mixing, and transport in a way that does not affect the dynamics of water flux volumes $V_{h} . Q_{e}$ is the exchange flux between active storage and passive storage. $i_{h}$ and $i_{\text {pas }}$ are the $\delta \mathrm{D}$ signature of the active storage and passive storage. For full details how water and isotope fluxes, storage and water age dynamics are simulated, the reader is referred to Zhang et al. (2019).

The modelling framework was built upon a coupled hydrological and tracer model and calibrated to high temporal resolution hydrometric and isotopic data at the outflow of the Chenqi catchment. Using flow and isotopic composition as calibration targets, objective functions (the modified Kling-Gupta efficiency, KGE) were combined to formulate a single measure of goodness of fit. Additionally, other data such as discharge and stable isotope signatures of the hillslope spring and isotopes in the depression wells were used as qualitative "soft" data to aid model evaluation. A Monte Carlo analysis was used to explore the parameter space during calibration and the modelling uncertainty. A total of $10^{5}$ different parameter combinations within the initial ranges were randomly generated as the possible parameter combinations. From the total of $10^{5}$ tested different parameter combinations, only the best (in terms of the efficiency statistics) parameter populations (500 parameter sets) were retained and used for further analysis. The results showed that this model could capture the flow and tracer dynamics within each landscape unit quite well. In the earlier paper, we showed the strong capacity of this tracer-aided model to track hourly water and isotope fluxes through each landscape unit and estimate the associated storage and water age dynamics. The model could also estimate the ages of water draining the hillslope unit, as well as the fast and slow flow reservoirs (Zhang et al., 2019).

In this study, water flux and storage dynamics were tracked by a tracer-aided model. The tracer-aided model with the calibrated parameters was run multiple times in parallel, tracking the fate of each rainfall event separately. The water from each rainfall hour was uniquely labelled with a specific tracer concentration. In this way, the variation in tracer concentration through time in each water store can be tracked, which reveals the transit time distribution (TTD) and water age distribution of water flux. This method, also used by Remondi et al. (2018), reflects solely the quantity we introduced and for which we know the origin. A total of 892 rainfall events (i.e. rainfall hours) during the study period of 11 November 2016 to 31 October 2017 were separately tracked. Tracking all the hourly inputs of precipitation over the study period and their individual paths to the outlets of hillslope, slow and fast reservoirs enabled the computation of the TTD of rainfall water entering the catchment, the age distribution and young water fraction $\left(\mathrm{F}_{\mathrm{yw}}\right)$ of water flux.

\section{Results}

\section{Young water fraction of water fluxes in different landscape units}

The $\mathrm{F}_{\mathrm{yw}}$ of water fluxes from the different landscape units were tracked using the tracer-aided model and calibrated parameter sets (Fig. 3). The simulated mean $\mathrm{F}_{\mathrm{yw}}$ were $0.39,0.31$ and 0.10 for the hillslope unit, fast flow and slow flow reservoirs during the study period. The seasonal differences in $\mathrm{F}_{\mathrm{yw}}$ are significant for all the conceptual stores. The mean $\mathrm{F}_{\mathrm{yw}}$ of water flux increased between the dry and wet seasons: ranging from 0.30, 0.07 and 0.03 for the dry season (December to the next April) to 0.48, 0.54 and 0.17 for the wet season (May to October), for the hillslope unit, fast flow and slow flow reservoirs, respectively. The mean $\mathrm{F}_{\mathrm{yw}}$ of runoff at the catchment outlet (fast flow reservoir) was mainly affected by the varying contributions of the major water sources in different seasons. In the dry season, a high proportion of flow was contributed by the slow flow reservoir to the runoff at the catchment outlet (the largest proportion was $78.4 \%$ from Zhang et al., 2019) leading to the low $\mathrm{F}_{\mathrm{yw}}$ of runoff at catchment outlet. In the wet season, the $\mathrm{F}_{\mathrm{yw}}$ of runoff had increased significantly because the hillslope unit contributes much more water to runoff at the catchment outlet $(57.5 \%)$, which was much younger than the water in the slow flow reservoir.

There is a noteworthy phenomenon that the mean $\mathrm{F}_{\mathrm{yw}}$ of the water flux in the hillslope unit was higher than that at the catchment outlet in the dry season (0.30 vs. 0.07$)$, but it was reversed in the wet season $(0.48$ vs. 0.54 ); this is likely to be due to the impact of sinkholes in the lower catchment. During heavy storm events, overland flow and epikarst water mainly directly generated by high intensity rainfall were collected 
by sinkholes and large fractures and recharged to the underground stream (flow out the catchment) directly. After this influx of younger water, the $\mathrm{F}_{\mathrm{yw}}$ at the catchment outlet increased rapidly, and therefore was higher than that in the hillslope unit during the wet season. The $\mathrm{F}_{\mathrm{yw}}$ of both flow in hillslope unit and catchment changed significantly during rainfall events, especially during the wet season. For example, the $\mathrm{F}_{\mathrm{yw}}$ of flow from hillslope unit and catchment outlet rose from 0.5 to close to 1 (Fig. 3).

We also calculated $F_{y w}$ of runoff using sine-wave approach proposed by Kirchner (2016a) in this study. Although this methodology has been successfully used at a number of sites (Jasechko et al., 2016; Song et al., 2017; Lutz et al., 2018; von Freyberg et al., 2018), it has not been widely tested for karst catchments due to the lack of data and high spatial heterogeneity. The seasonal cycle amplitudes $A_{s}$ and $A_{p}$ in Eq. (1) and (2) were determined according to the sinusoidal fits (Fig. 4), and the sine regression models of precipitation and runoff at the hillslope spring and catchment outlet were all statistically significant $(\mathrm{p}<0.00001)$. Using this approach, the $\mathrm{F}_{\mathrm{yw}}$ for the hillslope spring and catchment outlet were 0.07 and 0.09 , respectively. Although the sine regression was statistically significant for daily stable isotope values of rainfall, runoff at the hillslope spring and catchment outlet, the values obtained by sine-wave method were notably smaller than those determined by tracer-aided model tracking ( 0.39 and 0.31 for hillslope and outlet). This suggests that the $\mathrm{F}_{\mathrm{yw}}$ calculated using the sine-wave fitting method with daily isotope data is underestimated in this study catchment. The uncertainty of the sine-wave fitting method for $\mathrm{F}_{\mathrm{yw}}$ has been discussed in other studies. For example, Stockinger et al. (2016) found that the tracer sampling frequency markedly influenced estimation of $\mathrm{F}_{\mathrm{yw}}$, and weekly isotope tracer data lack information about faster water transport mechanisms in the catchment. However, the daily isotope tracer data used in some $\mathrm{F}_{\mathrm{yw}}$ calculations (Stockinger et al., 2016; Song et al., 2017) is also less well-suited for determining $F_{y w}$ using the sine-wave approach in a karst catchment, because it does not adequately capture the sub-daily variability in rainfall isotope signatures at resolution appropriate to the response times of sub-tropical karst systems (Coplen et al., 2008). Therefore, there is high uncertainty using the sine-wave approach with relatively low-frequency measurements of tracer behaviour collected daily or weekly, to calculate the $\mathrm{F}_{\mathrm{yw}}$ of runoff in catchments with rapidly variable flow dynamics, although it can reflect the seasonal tracer cycles. At present, there is a significant challenge in applying this method to determine the $\mathrm{F}_{\mathrm{yw}}$ in karst areas, because of the high cost of long-duration continuous sampling at sub-daily, even hourly resolution.

Based on the $\mathrm{F}_{\mathrm{yw}}$ calculated by flux tracking using the tracer-aided model, the discharge of 'old water' (i.e. with and age $>69$ days) were estimated for hillslope and catchment outlet (Fig. 5). The model results indicate that more rapid old water turnover occurs in wet season, although the $\mathrm{F}_{\mathrm{yw}}$ in wet season is obviously higher than in the dry season (Fig.3b). The mean discharge of old water was $7.8 \times 10^{-4}$ and $3 \times 10^{-5} \mathrm{~m}^{3} / \mathrm{s}$ for the hillslope and catchment outlet, respectively, during the dry period, and were $3.9 \times 10^{-3}$ and $5.8 \times 10^{-5}$ $\mathrm{m}^{3} / \mathrm{s}$ for the wet period. This indicates that in the rainy season, the young water (rain) enters soil and/or fractures/conduits and begins to displace the old water. These results are consistent with the reasoning by Harman (2019), that the old water release may be accelerated by high discharge or catchments wetness.

\section{Seasonal inter-relationships between storage and the young water fraction}

There is a marked seasonal variability in density distributions of $\mathrm{F}_{\mathrm{yw}}$ for the three conceptual stores (Fig.6 (a) and (b)). Due to the thin epikarst, with only a mean depth of $30 \mathrm{~cm}$ on the hillslopes (Zhang et al., 2013), even small rainfall events can lead to remarkable increases in $\mathrm{F}_{\mathrm{yw}}$ in the hillslopes The probability density distributions of $\mathrm{F}_{\mathrm{yw}}$ show that water fluxes in the hillslope unit and the catchment outlet (from fast flow reservoir) have much more pronounced changes compared to the slow flow reservoir for each month during the dry period (Fig. 6 (a)). The high proportion of water contributions from the slow reservoir to the catchment outlet caused the similar mean $\mathrm{F}_{\mathrm{yw}}(<0.05)$ for these two conceptual stores, although their density distributions are notably different over the dry season due to different responses to low rainfall infiltration. In each month during the wet period, the mean $\mathrm{F}_{\mathrm{yw}}$ of water flux from the hillslope unit was higher than from the outlet and slow flow reservoir, and also had the largest variety (from $\sim 0$ to more than 0.9 in Fig.6(b)).

Mean of the $\mathrm{F}_{\mathrm{yw}}$ and its variability demonstrate that the dominant water source of runoff at the catchment 
outlet has a controlling influence on the $\mathrm{F}_{\mathrm{yw}}$ of the water flux from the catchment. During responses to rainfall in the dry period, slow flow in the matrix or small fractures contributes a high proportion of older water to the underground channel at the catchment outlet, resulting in the low $\mathrm{F}_{\mathrm{yw}}$ of the catchment outlet; meanwhile, hillslope flow and direct rainfall recharge occasionally contribute to the outlet for some of the small rainfall events, resulting in the great changes of $\mathrm{F}_{\mathrm{yw}}$ at the catchment outlet. After heavy rain, the hillslope unit and direct rainfall recharge become the main water sources to the underground channel runoff, which can displace a large proportion of older water in the slow flow reservoir. Hence, the $\mathrm{F}_{\mathrm{yw}}$ of water flux for the outlet became very high (Fig.6).

Fig. 7 shows the respective modelled relationships between $\mathrm{F}_{\mathrm{yw}}$ of water fluxes and the storage of the hillslope unit, and fast and slow flow reservoirs. For the hillslope unit, when storage was low for most rainfall events in the dry season, the $\mathrm{F}_{\mathrm{yw}}$ of water flux usually increases sharply above a specific water storage, giving marked hysteresis (Fig.7(a)). Below the specific water storage, small rainfall amounts can rapidly recharge the aquifer, and substantially increase the relatively small hillslope storage. Furthermore, as there is no additional young water to maintain recharge the hillslope unit once rainfall stops, there is a rapid decline in $\mathrm{F}_{\mathrm{yw}}$. Under higher storage conditions (in the wet season), the $\mathrm{F}_{\mathrm{yw}}$ of water flux tends to be a significant linear increase with storage in a prolong time.

For the slow flow reservoir, there was a strong season hysteretic pattern of $\mathrm{F}_{\mathrm{yw}}$ of modelled flux vs. water storage (Fig.7(b)). During the dry period, water stored in small fractures is released to the underground channel without inputs of young water in rainfall. Therefore, the $\mathrm{F}_{\mathrm{yw}}$ nearly stayed constant between November and April $(<0.05)$, with the steady decrease in storage (from ${ }^{\sim} 280$ to $200 \mathrm{~mm}$ ). During the wet season (May to August), the $\mathrm{F}_{\mathrm{yw}}$ increased linearly with the increase in water storage, because of consecutively new rainwater recharge. In the later rainfall period (September and October) when the slow flow reservoir storage reaches the highest, there was a little change in storage with the gradually ageing water (Fig.7(b)), mainly sustained by the hillslope unit (Zhang et al., 2019).

For the fast flow contributions to outflows at the catchment outlet, there was a large variation in $\mathrm{F}_{\mathrm{yw}}$ of water flux (from $\sim 0$ to 0.8 ) because water storage in the fast flow reservoir (conduits) was low (Fig.7(c)). Particularly, the very narrow range of water storage $(<1 \mathrm{~mm})$ for low $\mathrm{F}_{\mathrm{yw}}$ indicates that variation in the outlet $\mathrm{F}_{\mathrm{yw}}$ is caused by some fast flow (young water) that rarely has time to enter storage, as shown by the sharp increases of the hillslope flow in the dry period. As the $\mathrm{F}_{\mathrm{yw}}$ becomes high, the band of water storage increases, which corresponds to the linear relationship between the $\mathrm{F}_{\mathrm{yw}}$ and storage during the wet season (Fig.7(a) and 7(b)). This means that much more young water (high $\mathrm{F}_{\mathrm{yw}}$ ) from the hillslope unit and direct infiltration of rainfall fills in the underground channel, and then quickly mixes with or displaces the older water at the catchment outlet. During the wettest periods when the $\mathrm{F}_{\mathrm{yw}}$ becomes highest (e.g. $\left.>0.7\right)$, a marked increase in storage occurs, however the $\mathrm{F}_{\mathrm{yw}}$ sometimes did not increase dramatically. This means that after large quantities of young water from the hillslope unit and direct rainfall infiltration (via sinkholes) simultaneously drain into the underground channel in wet time, the fast flow reservoir has been almost filled with young water even though the storage changes with the rise and decline of hydrographs.

\section{Time variance of the water age and travel time distributions}

The water age pdfs (probability density function) of runoff at outlet of hillslope unit and the catchment (reflecting the integration of the residence times of the contributing water storages) are drawn from a series of tracer-aided model simulations where the water dynamics in each conceptual store are driven by rainfall input over specific periods (Fig. 8). In this study, three times were chosen $(t 1: 30$ November 2016; $t 2: 11$ March 2017 and $t 3: 12$ June 2017) for water age pdf of runoff estimation. These specific times reflect dry conditions (11 March 2017), wet conditions (12 June 2017) and the midpoint (30 November 2016) of the study period (the rainfall and discharge characteristics at each time at the hillslope and outlet are shown in Table 1). The results in Fig. 8 show noticeable differences among the water age pdfs corresponding to the three different times. The water age pdfs show a series of pronounced spikes reflecting the impact of the rainfall input within the catchment (shown in Fig. 8). In the dry period, water age of outflow from the hillslope store and catchment outlet are dominated by the old water release. For example, the youngest water with the age 
of 0 day (the rainfall water converting to outflow at the same rain day) only accounts for $21 \%$ and $0.5 \%$ of the total discharge at hillslope and catchment outlet on 30 November 2016. In contrast, the probability of a water age of 0 days was $60 \%$ and $80 \%$ for the hillslope and catchment outlet, respectively, on 12 June 2017. The time variability in pdf of runoff water age indicates a strong and direct effect of precipitation and storage conditions on the shape of individual water age pdfs, both of which affect the time of water exiting the catchment. It is particularly noticeable that the differences in water age pdfs between dry and wet season for runoff at the catchment outlet are much larger than that for the hillslope. For example, the probabilities of a water age of 0 days are $21 \%$ to $60 \%$ for the hillslope but $0.5 \%$ to $80 \%$ for the catchment outlet, in dry and wet season. The high storage capacity of the slow flow reservoir in the depression in dry periods can accommodate most rainwater, leading to older water flowing out of the catchment quickly. However, during the wet period, substantial proportions of high intensity rainfall recharge the large fractures and conduits. Therefore, most young water flows out of the catchment through the hydrologically connected flow paths between the hillslope and underground channel, or via sinkholes/large fractures increasing the young water fraction of runoff significantly (Fig.8).

Fig.9 shows the forward-projected transit time distribution (TTD) of rain water entering the catchment on the three dates considered in Fig. 8: this shows the distribution of how long rainfall water entering the system at the reference time of $t_{i}(i=1,2,3$ in Fig. 9) will spend transiting through the system before it reaches the outlet (Benettin et al., 2015b). The difference among the three transit time pdfs again highlights the effect of time-variance on the transport dynamics emerging at the catchment scale as a result of successive rainfall inputs. Each transit time pdf corresponding to the three start times is multimodal, with more or less pronounced peaks whose magnitudes are strongly synchronous with the hydrologic dynamics. In addition, the temporal evolution of the hillslope and catchment outlet flows $\left(Q_{s}\right.$ and $Q$, respectively), are evidence of the correlation between the position of the transit time pdf spikes and the occurrence of the flood events (Fig. 9). The results show that the TTD of entering rain water is affected by the discharge (reflecting the displacement of storage in corresponding conceptual stores). When there was a flood, this part of "old" water stored in the aquifer is displaced in large quantities at high discharge rates (the peaks of pdf in July and August in 2017 shown in Fig.9a and b).

Although the mean transit time (MTT) cannot be calculated from the simulation results due to the short simulation period (only one year), the catchment and hillslope unit controls on the inflow water can be evaluated from the transit time pdfs. For the dry conditions (11 March 2017) with the rainfall of $0.4 \mathrm{~mm}$, only $6 \%$ of inputs rain water exited the catchment through the conduit over the period from this rain day to the end of the simulation time, a total of 233 days. For the midpoint of this study period (30 November 2016 ) with the rainfall of $3.9 \mathrm{~mm}$, the same percentile of $6 \%$ of inputs rain water exiting the catchment took 225 days. For the wet conditions (12 June 2017) with the rainfall of $45.6 \mathrm{~mm}, 16 \%$ of inputs rain water exited the catchment on that day, and $6 \%$ of inputs rainfall water exiting the catchment only took about 3 hours. The results indicate that most of water entering in dry periods (mainly after the light rains) is stored in the catchment for a long time with high mean transit time. In contrast, in wet periods considerable proportion of new water will exit the catchment in a short time. The patterns of the transit time of outflow from the hillslope unit are similar as the catchment, and $6 \%$ of inputs rainfall water exiting the hillslope unit took 203, 106 and about 0.1 days, respectively.

\section{Discussion}

\section{Influence of hydrological connectivity on $\mathbf{F}_{\mathbf{y w}}$ in karst critical zone}

Although much recent research has focused on estimating the mean annual $\mathrm{F}_{\mathrm{yw}}$ (von Freyberg et al., 2018; Wilusz et al., 2017) and short-term responses of $\mathrm{F}_{\mathrm{yw}}$ to changes during precipitation events; the influence of storage (i.e. catchment wetness) and/or discharge on catchment dynamics is less clear (Kirchner, 2016b; Lutz et al., 2018; von Freyberg et al., 2018; Wilusz et al., 2017). In essence, temporal changes in hydrological connectivity, driven by storage dynamics, directly lead to changes in the $\mathrm{F}_{\mathrm{yw}}$ of runoff. In karst environments, the change in hydrological connectivity and its impact on the $\mathrm{F}_{\mathrm{yw}}$ is particularly pronounced. For example, the $\mathrm{F}_{\mathrm{yw}}$ of water fluxes increases as hydrological connectivity between the hillslope and depression is strengthened 
during the wet period. In addition to infiltration through fractures within the epikarst matrix, concentrated infiltration from surface to underground flow systems via sinkholes is a distinct aspect of $\mathrm{F}_{\mathrm{yw}}$ in karst catchments. This can make the $\mathrm{F}_{\mathrm{yw}}$ at catchment outlet close to 1 (Fig. 3). In addition, the bidirectional flow exchange between matrix/small fractures and conduits or large fractures, controlled by their respective water levels, is a unique feature of karstic areas (Zhang et al, 2017). When the old water from the matrix enters the conduits, or the young water from the conduits flows back to the matrix, the $\mathrm{F}_{\mathrm{yw}}$ of both water stores will be changed. Although new water from the conduits has a small impact on the age of the large volume of storage in the slow flow reservoir (the $\mathrm{F}_{\mathrm{yw}}$ of fluxes from the slow flow reservoir did not change as drastically as other conceptual stores), there is still an impact on the $\mathrm{F}_{\mathrm{yw}}$ of water in the small fractures around the larger conduits. Although this component of the younger entrance water will reduce the age of the water in the small fractures around conduits, the latter have the potential to be contaminated, which may have implications for water quality studies.

This is an important issue in the study catchment as fertilization of crops mainly occurs immediately prior to the rainy season, and large quantities of pollutants, such as inorganic nitrogen, remain on the surface (Yue et al., 2019). When heavy rain occurs, the component that enters the underground channel with water flowing through sinkholes or large fractures can transport this contamination into small fractures where it can be stored in the aquifer (Yue et al., 2019). This creates a small, but critical, part of the aquifer that is highly vulnerable to pollution, although its age may be relatively low in the wet season compared to the slow flow reservoir. High young water contributions reflect strong hydrological connectivity between underground channels and the catchment hillslopes via large fractures or from the surface via sinkholes. This means the high $\mathrm{F}_{\mathrm{yw}}$ is likely related to cleaner water sources in hillslope draining non-agricultural forest and shrubs (Xiao et al., 2013) or surface contaminants in the lowland depression derived from agriculture (e.g. nitrogen). Hence, it is important to assess the role of hydrological connectivity and quantify its influence on the $\mathrm{F}_{\mathrm{yw}}$ in the karst critical zone and associated interactions with biogeochemical processes. In particular, land and water management scenarios within karst watersheds need to not only consider the solute fluxes within the surface or underground system, but also the direct transfer of solutes between them via sinkholes. Young water comprises $\sim 30 \%$ of the total runoff in this catchment, indicating that watersheds can transmit large contributions of soluble contaminant inputs to streams over much shorter time periods. This is consistent with recent global scale analysis that has emphasises the importance of young water contributions to larger rivers (Jasechko et al., 2016). However, in karst systems, due to the bidirectional flow between the fast and slow flow reservoirs, the soluble contaminant inputs to the small fractures or matrix in aquifer creates a "memory effect" of pollutant inputs that can be a significant pollutant source to streams, even the $\mathrm{F}_{\mathrm{yw}}$ is high, especially at the beginning of wet season.

\section{The turnover of old water in storage}

The "old water paradox" has been a focus of interest for hydrologists; this addresses the question of how catchments store water for weeks or months, but then release it in minutes or hours in response to rainfall inputs (Kirchner, 2003). This is closely related to understanding dominant streamflow generation processes and associated solute fluxes, and provides insight into the difference between the velocity of water particles and the celerity of the response of hydrological systems (McDonnell and Beven, 2014). Fig. 5 shows that as discharge increases at Chenqi, the release of both young and old water at the hillslope spring and catchment outlet increase. The short-term rainfall-runoff dynamics (over hours) are controlled by the celerity of catchment or hillslope responses, which mobilizes water that has usually been stored in the catchment for much longer periods (months to years), but is constrained by low pore velocities. However, the increment is disproportionately larger for younger storage than it is for older, indicating that the increase in discharge is increasingly driven by the release of young water. This rapid increase in younger water contributions with increasing storage and discharge has been termed the 'inverse storage effect' by Harman (2015), which reduces the age of the water in the storage (Fig.10 in Zhang et al., 2019). Despite the 'inverse storage effect', at Chenqi, displacement of old water is also accelerated at moderately high flows, and this is consistent with the results of water age pdfs in Fig. 8. Although the $\mathrm{F}_{\mathrm{yw}}$ was $~ 80 \%$ for runoff on 12 June 2017, the high discharge (0.0013 and $0.15 \mathrm{~m}^{3} / \mathrm{s}$ for the hillslope unit and catchment outlet, respectively) still resulted 
in large amounts of old water to be drained. This is consistent with findings on nutrient dynamics in the catchment reported by Yue et al., (2019). Based on nitrate $\left[\mathrm{NO}_{3}{ }^{-}-\mathrm{N}\right]$ and the discharge time series of the study catchment in the wet season of 2017, they found that maximum nitrate concentrations during storm events generally lags behind peak $Q$, which indicates that initially water is low in nitrate and then sources with greater nitrate concentrations become increasingly important. In contrast, the $\mathrm{F}_{\mathrm{yw}}$ of runoff in the dry period (30 November 2016 and 11 March 2017) were much lower than that in the wet period, but only small volumes of old water were released due to the low discharge at the hillslope and catchment outlet.

In this study, the changes in isotope composition from rainwater to the water flow at the hillslope spring and catchment outlet are also consistent with the hypothesis that old water acceleration is also occurring during high flows. The $\delta \mathrm{D}$ values at the sampling points in this catchment for the two largest rainfall events in 2017 are listed in Table 2. It shows that $\delta \mathrm{D}$ values at the outlet and hillslope spring are much less negative than rainwater. This is most likely explained by strong mixing of young rainwater with old stored water during and after the rainfall, although celerity of the response of discharge to rainfall is fast. This suggests that there was substantial old water delivered to the underground conduits at high discharge; and would be consistent with the aforementioned water quality studies which showed that the $\mathrm{NO}_{3}^{-}$concentration in runoff at the catchment outlet increased significantly after heavy rainfall, and then fell back to a low level as flows decreased (Yue, et al., 2019).

\section{Broader Implications for land and water management in karst area}

Nitrogen fertilizer is a predominant contributor of nitrogen pollution in many karst catchments worldwide (Panno et al, 2001; Minet et al., 2017; Eller and Katz, 2017). Especially, in southwest China, one of the largest and continuous karst areas in the world, the agricultural activities are the main cause of aquifer nitrate pollution (Yang et al., 2013). In this area, farmers usually apply fertilizer in May and November. According to the transit time pdfs shown in Fig.9, in the dry season, most rainfall inputs will be stored in aquifer for many months before they exit the catchment. That means a significant portion of nitrogen from the fertilizer used in dry period (November) will be released slowly for a long time, leading the chronic aquifer nitrate pollution. Denitrification from water via emission of gases is the main mechanism of nitrogen removal, and reaction rates in karst areas are very fast, and can reach $15 \mathrm{mg} \mathrm{N} \cdot \mathrm{m}^{2} / \mathrm{d}$ (Heffernan et al., 2012). According to the results by Yue et al., (2015), denitrification removes about $46.7 \%$ of the nitrate in this area, and the ratio is similar to that in other karst area, such as $36 \%$ in Kentucky, USA (Husic et al., 2019). Although long residence times may increase the potential for denitrification (Albertin et al., 2012; Han et al., 2015), there is also substantial residual nitrogen remaining in the karstic aquifer (Yue et al., 2019). Therefore, improving the efficiency of fertilization is an urgent need to reduce the nitrate contamination.

The largest agricultural fertilization in the region where the Chenqi catchment is based typically occurs in May, corresponding to the end of the dry season and beginning of the wet season. The more rapid flows with short transit times of rainfall inputs, occur via large fractures (i.e. sinkholes) and from steeper hillslopes unit, and contributed most flow at the outlet in wet season (Zhang et al., 2017, 2019). Hence, during heavy rainfall events, nitrogen from fertilizer will rapidly infiltrate to the aquifer and flow out the catchment through surface stream or underground channel, leading to the nitrogen loss. Especially, the sinkholes, mainly distributed in valleys covered by thick soil with high $\mathrm{N}$ inputs due to local fertilizer applications, increase the concentrated, rapid loss of nitrogen in karst critical zone during wet period. According to the results from Yue et al., (2019), in the wet season, up to $94 \%$ of annual nitrate export from the headwater catchments occurred within two months. Therefore, fertilization timing to earlier in the growing season and restricted application around sinkholes may help to loss of $\mathrm{N}$ during large storm events.

\section{Conclusions}

This study determined the TTD and $\mathrm{F}_{\mathrm{yw}}$ in different landscape units within a karst catchment in Chenqi in Southwest China, using a tracer-aided conceptual hydrological model. The simulated mean $\mathrm{F}_{\mathrm{yw}}$ were 0.39 , 0.31 and 0.10 for the hillslope, fast flow and slow flow reservoirs, respectively. We also estimated the young water fraction using the sine-wave method based on the daily observations of stable isotopes. Such relatively 
low-frequency measurements of tracer dynamics fitted by the sine-wave approach significantly underestimate $\mathrm{F}_{\mathrm{yw}}$ in karst systems marked seasonal variability in sources of runoff generation, and hydrological connectivity between different conceptual stores, were the main drivers of $\mathrm{F}_{\mathrm{yw}}$ dynamics in each landform unit. Affected by sinkholes and large fractures, young water recharges the underground channel quickly after heavy rainfall, leading to significant increases in the $\mathrm{F}_{\mathrm{yw}}$ of runoff (close to 1). The results of transit time pdfs for three rainfall events representing different catchment wetness conditions indicated that the forward TTD of new water was markedly affected by the water storage of corresponding conceptual stores. Most rainwater is stored in the aquifer (matrix or small fractures) when rainfall events occur during the dry period, and this stored water is released quickly during floods in the wet period, which has an important influence on water quality in the catchment. After heavy rainfall events in the wet season, there is rapid and direct rainfall conversion to underground flow through large fractures and sinkholes. Even though the contribution of young water to runoff is greater at high flows, the old water contribution is generally accelerated as well. Meanwhile, there was strong mixing of the younger rainwater with old stored water during and after the rainfall, decreasing turnover times. However, the tracer-aided model used here is a conceptual, and can only to assess the spatial variations in transit time and water age between the dominant landscape units in complex karst terrain. Consequently, more complex tracer-aided process-based modelling is needed for finer spatial insights.

Data Availability Statement: The data that support the findings of this study are available from the corresponding author upon reasonable request.

Acknowledgments. This research was supported by the UK-China Critical Zone Observatory (CZO) Programme (41571130071), the National Natural Science Foundation of China (41971028, 41571020, 41601013), the National Key Research and development Program of China (2016YFC0502602) and the UK Natural Environment Research Council (NE/N007468/1).

\section{References}

Albertin, A.R., Sickman, J.O., Pinowska, A., \& Stevenson, R.J. (2012). Identification of nitrogen sources and transformations within karst springs using isotope tracers of nitrogen. Biogeochemistry , 108 (1-3), 219-232. doi: 10.1007/s10533-011-9592-0

Bakalowicz, M. (2005). Karst groundwater: a challenge for new resources.Hydrogeology Journal , 13 (1), 148-160. doi: 10.1007/s10040-004-0402-9

Benettin, P., Kirchner, J.W., Rinaldo, A., \& Botter, G. (2015a). Modeling chloride transport using travel time distributions at Plynlimon, Wales. Water Resources Research , 51 (5), 3259-3276. doi: 10.1002/2014WR016600

Benettin, P., Rinaldo, A., \& Botter, G. (2015b). Tracking residence times in hydrological systems: forward and backward formulations. Hydrological Processes , 29 (25), 5203-5213. doi: 10.1002/hyp.10513

Birkel, C., Soulsby, C., Tetzlaff, D., Dunn, S., \& Spezia, L. (2012). High-frequency storm event isotope sampling reveals time-variant transit time distributions and influence of diurnal cycles. Hydrological Processes , 26 (2), 308-316. doi: 10.1002/hyp.8210

Birkel, C., \& Soulsby, C. (2015). Advancing tracer-aided rainfall-runoff modelling: a review of progress, problems and unrealised potential. Hydrological Processes , 29 (25), 5227-5240. doi: 10.1002/hyp.10594

Burt, T.P., \& McDonnell, J.J. (2015). Whither field hydrology? The need for discovery science and outrageous hydrological hypotheses. Water Resources Research , 51 (8), 5919-5928. doi: 10.1002/2014WR016839

Chen, X., Zhang, Z., Soulsby, C., Cheng, Q., Binley, A., Jiang, R., \& Tao, M. (2018). Characterizing the heterogeneity of karst critical zone and its hydrological function: An integrated approach.Hydrological Processes , 32 (19), 2932-2946. doi: 10.1002/hyp.13232

Coplen, T.B., Neiman, P.J., White, A.B., Landwehr, J.M., Ralph, F.M., \& Dettinger, M.D. (2008). Extreme changes in stable hydrogen isotopes and precipitation characteristics in a landfalling Pacific storm. Geophysical 
Research Letters , 35 (21), L21808. doi: 10.1029/2008GL035481

Eller, K.T., \& Katz, B.G. (2017). Nitrogen Source Inventory and Loading Tool: An integrated approach toward restoration of water-quality impaired karst springs. Journal of Environmental Management, 196, 702-709. doi: 10.1016/j.jenvman.2017.03.059

Ford, D., \& Williams, P. (2013). Speleogenesis: The Development of Cave Systems. In Karst Hydrogeology and Geomorphology John Wiley \& Sons Ltd,.: West Sussex, England; 209-270. doi: 10.1002/9781118684986.ch7

Han, D., Cao, G., McCallum, J., \& Song, X. (2015). Residence times of groundwater and nitrate transport in coastal aquifer systems: Daweijia area, northeastern China. Science of The Total Environment , 538, 539-554. doi: 10.1016/j.scitotenv.2015.08.036

Harman, C.J. (2019). Age-Ranked Storage-Discharge Relations: A Unified Description of Spatially Lumped Flow and Water Age in Hydrologic Systems. Water Resources Research , 55 (8), 7143-7165. doi: 10.1029/2017WR022304

Harman, C.J. (2015). Time-variable transit time distributions and transport: Theory and application to storage-dependent transport of chloride in a watershed. Water Resources Research , 51 (1), 1-30. doi: 10.1002/2014WR015707

Hartmann, A., Goldscheider, N., Wagener, T., Lange, J., \& Weiler, M. (2014a). Karst water resources in a changing world: Review of hydrological modeling approaches. Reviews of Geophysics , 52 (3), 218-242. doi: 10.1002/2013RG000443

Hartmann, A., Kobler, J., Kralik, M., Dirnbock, T., Humer, F., \& Weiler, M.(2014b). Deriving the timevariant transit time distributions of an Austrian karst system by a semi-distributed karst model. Conference: EGU General Assembly.

Heffernan, J.B., Albertin, A.R., Fork, M.L., Katz, B.G., \& Cohen, M.J. (2012). Denitrification and inference of nitrogen sources in the karstic Floridan Aquifer. Biogeosciences , 9 (5), 1671-1690. doi: 10.5194/bg-9$1671-2012$

Heidbuchel, I., Troch, P.A., \& Lyon, S.W. (2013). Separating physical and meteorological controls of variable transit times in zero-order catchments. Water Resources Research , 49 (11), 7644-7657. doi: 10.1002/2012WR013149

Hrachowitz, M., Benettin, P., van Breukelen, B.M., Fovet, O., Howden, N.J.K., Ruiz, L., van der Velde, Y., \& Wade, A.J. (2016). Transit times-the link between hydrology and water quality at the catchment scale. Wiley Interdisciplinary Reviews: Water , 3 (5), 629-657. doi: 10.1002/wat2.1155

Hrachowitz, M., Savenije, H., Bogaard, T.A., Tetzlaff, D., \& Soulsby, C. (2013). What can flux tracking teach us about water age distribution patterns and their temporal dynamics? Hydrology and Earth System Sciences , 17 (2), 533-564. doi: 10.5194/hess-17-533-2013

Hrachowitz, M., Soulsby, C., Tetzlaff, D., Dawson, J.J.C., \& Malcolm, I.A. (2009). Regionalization of transit time estimates in montane catchments by integrating landscape controls. Water Resources Research , 45 (5) doi: 10.1029/2008WR007496

Hrachowitz, M., Soulsby, C., Tetzlaff, D., Malcolm, I.A., \& Schoups, G. (2010). Gamma distribution models for transit time estimation in catchments: Physical interpretation of parameters and implications for time-variant transit time assessment. Water Resources Research , 46 (10), 2010WR009148. doi: 10.1029/2010WR009148

Hu, K., Chen, H., Nie, Y., \& Wang, K. (2015). Seasonal recharge and mean residence times of soil and epikarst water in a small karst catchment of southwest China. Scientific Reports , 5 (1), 10215 . doi: $10.1038 /$ srep10215 
Husic, A., Fox, J., Adams, E., Ford, W., Agouridis, C., Currens, J., \& Backus, J. (2019). Nitrate Pathways, Processes, and Timing in an Agricultural Karst System: Development and Application of a Numerical Model. Water Resources Research , 55 (3), 2079-2103. doi: 10.1029/2018WR023703

Jasechko, S., Kirchner, J.W., Welker, J.M., \& McDonnell, J.J. (2016). Substantial proportion of global streamflow less than three months old.Nature Geoscience , 9 (2), 126-129. doi: 10.1038/ngeo2636

Kirchner, J.W. (2003). A double paradox in catchment hydrology and geochemistry. Hydrological Processes , 17 (4), 871-874. doi: 10.1002/hyp.5108

Kirchner, J.W. (2016a). Aggregation in environmental systems \&amp;ndash; Part 1: Seasonal tracer cycles quantify young water fractions, but not mean transit times, in spatially heterogeneous catchments. Hydrology and Earth System Sciences , 20 (1), 279-297. doi: 10.5194/hess-20-279-2016

Kirchner, J.W. (2016b). Aggregation in environmental systems \&amp;ndash; Part 2: Catchment mean transit times and young water fractions under hydrologic nonstationarity. Hydrology and Earth System Sciences , 20 (1), 299-328. doi: 10.5194/hess-20-299-2016

Kirchner, J.W., Feng, X., \& Neal, C. (2000). Fractal stream chemistry and its implications for contaminant transport in catchments. Nature , 403 (6769), 524-527. doi: 10.1038/35000537

Kuppel, S., Tetzlaff, D., Maneta, M.P., \& Soulsby, C. (2018a). EcH 2 O-iso 1.0: water isotopes and age tracking in a process-based, distributed ecohydrological model. Geoscientific Model Development, 11 (7), 3045-3069. doi: 10.5194/gmd-11-3045-2018

Kuppel, S., Tetzlaff, D., Maneta, M.P., \& Soulsby, C. (2018b). What can we learn from multi-data calibration of a process-based ecohydrological model? Environmental Modelling ES Software, 101, 301-316. doi: 10.1016/j.envsoft.2018.01.001

Lutz, S.R., Krieg, R., Muller, C., Zink, M., Knoller, K., Samaniego, L., \& Merz, R. (2018). Spatial Patterns of Water Age: Using Young Water Fractions to Improve the Characterization of Transit Times in Contrasting Catchments. Water Resources Research , 54 (7), 4767-4784. doi: 10.1029/2017WR022216

Maxwell, R.M., Condon, L.E., Kollet, S.J., Maher, K., Haggerty, R., \& Forrester, M.M. (2016). The imprint of climate and geology on the residence times of groundwater. Geophysical Research Letters , 43 (2), 701-708. doi: 10.1002/2015GL066916

McCallum, J.L., Engdahl, N.B., Ginn, T.R., \& Cook, P.G. (2014). Nonparametric estimation of groundwater residence time distributions: What can environmental tracer data tell us about groundwater residence time? Water Resources Research , 50 (3), 2022-2038. doi: 10.1002/2013WR014974

McDonnell, J.J., \& Beven, K. (2014). Debates-The future of hydrological sciences: A (common) path forward? A call to action aimed at understanding velocities, celerities and residence time distributions of the headwater hydrograph. Water Resources Research , 50 (6), 5342-5350. doi: 10.1002/2013WR015141

McGuire, K.J., \& McDonnell, J.J. (2006). A review and evaluation of catchment transit time modeling. Journal of Hydrology , 330 (3-4), 543-563. doi: 10.1016/j.jhydrol.2006.04.020

McMillan, H., Tetzlaff, D., Clark, M., \& Soulsby, C. (2012). Do time-variable tracers aid the evaluation of hydrological model structure? A multimodel approach. Water Resources Research , 48 (5) doi: 10.1029/2011WR011688

Minet, E.P., Goodhue, R., Meier-Augenstein, W., Kalin, R.M., Fenton, O., Richards, K.G., \& Coxon, C.E. (2017). Combining stable isotopes with contamination indicators: A method for improved investigation of nitrate sources and dynamics in aquifers with mixed nitrogen inputs. Water Research , 124, 85-96. doi: $10.1016 /$ j.watres.2017.07.041

Panno, S.., Hackley, K.., Hwang, H.., \& Kelly, W.. (2001). Determination of the sources of nitrate contamination in karst springs using isotopic and chemical indicators. Chemical Geology , 179 (1-4), 113-128. doi: 


\subsection{6/S0009-2541(01)00318-7}

Peralta-Tapia, A., Soulsby, C., Tetzlaff, D., Sponseller, R., Bishop, K., \& Laudon, H. (2016). Hydroclimatic influences on non-stationary transit time distributions in a boreal headwater catchment. Journal of Hydrology , 543, 7-16. doi: 10.1016/j.jhydrol.2016.01.079

R Development Core Team. (2017). R: A language and environment for statistical computing. Vienna, Austria DOI: R Foundation for Statistical Computing, Vienna, Austria. ISBN 3-900051-07-0, URL http://www.R-project.org.

Remondi, F., Kirchner, J.W., Burlando, P., \& Fatichi, S. (2018). Water Flux Tracking With a Distributed Hydrological Model to Quantify Controls on the Spatiotemporal Variability of Transit Time Distributions. Water Resources Research , 54 (4), 3081-3099. doi: 10.1002/2017WR021689

Seeger, S., \& Weiler, M. (2014). Reevaluation of transit time distributions, mean transit times and their relation to catchment topography. Hydrology and Earth System Sciences , 18 (12), 4751-4771. doi: 10.5194/hess18-4751-2014

Song, C., Wang, G., Liu, G., Mao, T., Sun, X., \& Chen, X. (2017). Stable isotope variations of precipitation and streamflow reveal the young water fraction of a permafrost watershed. Hydrological Processes , 31 (4), 935-947. doi: 10.1002/hyp.11077

Soulsby, C., Birkel, C., Geris, J., Dick, J., Tunaley, C., \& Tetzlaff, D. (2015). Stream water age distributions controlled by storage dynamics and nonlinear hydrologic connectivity: Modeling with high-resolution isotope data. Water Resources Research , 51 (9), 7759-7776. doi: 10.1002/2015WR017888

Stockinger, M.P., Bogena, H.R., Lucke, A., Diekkruger, B., Cornelissen, T., \& Vereecken, H. (2016). Tracer sampling frequency influences estimates of young water fraction and streamwater transit time distribution. Journal of Hydrology , 541, 952-964. doi: 10.1016/j.jhydrol.2016.08.007

von Freyberg, J., Allen, S.T., Seeger, S., Weiler, M., \& Kirchner, J.W. (2018). Sensitivity of young water fractions to hydro-climatic forcing and landscape properties across 22 Swiss catchments. Hydrology and Earth System Sciences , 22 (7), 3841-3861. doi: 10.5194/hess-22-3841-2018

White, W.B. (2007). Cave sediments and paleoclimate. Journal of Cave and Karst Studies.

Wilusz, D.C., Harman, C.J., \& Ball, W.P. (2017). Sensitivity of Catchment Transit Times to Rainfall Variability Under Present and Future Climates. Water Resources Research , 53 (12), 10231-10256. doi: 10.1002/2017WR020894

Worthington, S.R.H. (2009). Diagnostic hydrogeologic characteristics of a karst aquifer (Kentucky, USA). Hydrogeology Journal , 17 (7), 1665-1678. doi: 10.1007/s10040-009-0489-0

Xiao, H.-W., Xiao, H.-Y., Long, A.-M., Wang, Y.-L., \& Liu, C.-Q. (2013). Chemical composition and source apportionment of rainwater at Guiyang, SW China. Journal of Atmospheric Chemistry , 70 (3), 269-281. doi: $10.1007 / \mathrm{s} 10874-013-9268-3$

Yang, P., Yuan, D., Ye, X., Xie, S., Chen, X., \& Liu, Z. (2013). Sources and migration path of chemical compositions in a karst groundwater system during rainfall events. Chinese Science Bulletin , 58 (20), 2488-2496. doi: 10.1007/s11434-013-5762-x

Yue, F.-J., Li, S.-L., Liu, C.-Q., Lang, Y.-C., \& Ding, H. (2015). Sources and transport of nitrate constrained by the isotopic technique in a karst catchment: an example from Southwest China.Hydrological Processes , 29 (8), 1883-1893. doi: 10.1002/hyp.10302

Yue, F.-J., Waldron, S., Li, S.-L., Wang, Z.-J., Zeng, J., Xu, S., Zhang, Z.-C., \& Oliver, D.M. (2019). Land use interacts with changes in catchment hydrology to generate chronic nitrate pollution in karst waters and strong seasonality in excess nitrate export. Science of The Total Environment , 696, 134062. doi: 10.1016/j.scitotenv.2019.134062 
Zhang, Z., Chen, X., Cheng, Q., \& Soulsby, C. (2019). Storage dynamics, hydrological connectivity and flux ages in a karst catchment: conceptual modelling using stable isotopes. Hydrology and Earth System Sciences , 23 (1), 51-71. doi: 10.5194/hess-23-51-2019

Zhang, Z., Chen, X., \& Soulsby, C. (2017). Catchment-scale conceptual modelling of water and solute transport in the dual flow system of the karst critical zone. Hydrological Processes, 31 (19), 3421-3436. doi: 10.1002/hyp.11268

Zhang, Z., Chen, X., Chen, X., \& Shi, P. (2013). Quantifying time lag of epikarst-spring hydrograph response to rainfall using correlation and spectral analyses. Hydrogeology Journal , 21 (7), 1619-1631. doi: $10.1007 / \mathrm{s} 10040-013-1041-9$

Zhang, Z., Chen, X., Ghadouani, A., \& Shi, P. (2011). Modelling hydrological processes influenced by soil, rock and vegetation in a small karst basin of southwest China. Hydrological Processes , 25 (15), 2456-2470. doi: $10.1002 /$ hyp. 8022

\section{Hosted file}

Transit times and young water ages-zhang-SI-HP-table1.docx available at https://authorea. com/users/291479/articles/418756-characterising-the-variability-of-transit-timedistributions-and-young-water-fractions-in-a-karst-catchment-using-flux-tracking

\section{Hosted file}

Transit times and young water ages-zhang-SI-HP-table2.docx available at https://authorea. com/users/291479/articles/418756-characterising-the-variability-of-transit-timedistributions-and-young-water-fractions-in-a-karst-catchment-using-flux-tracking

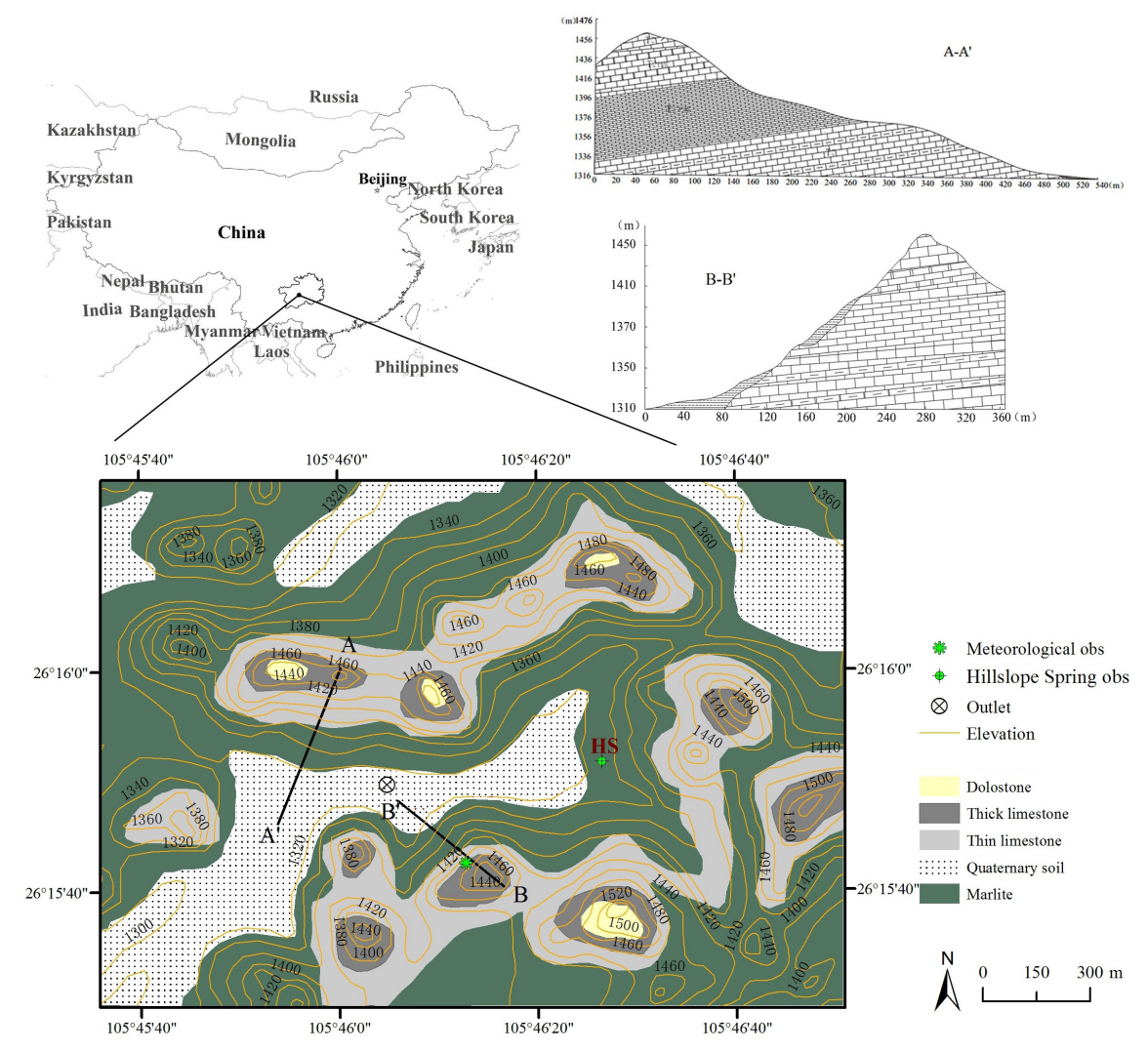




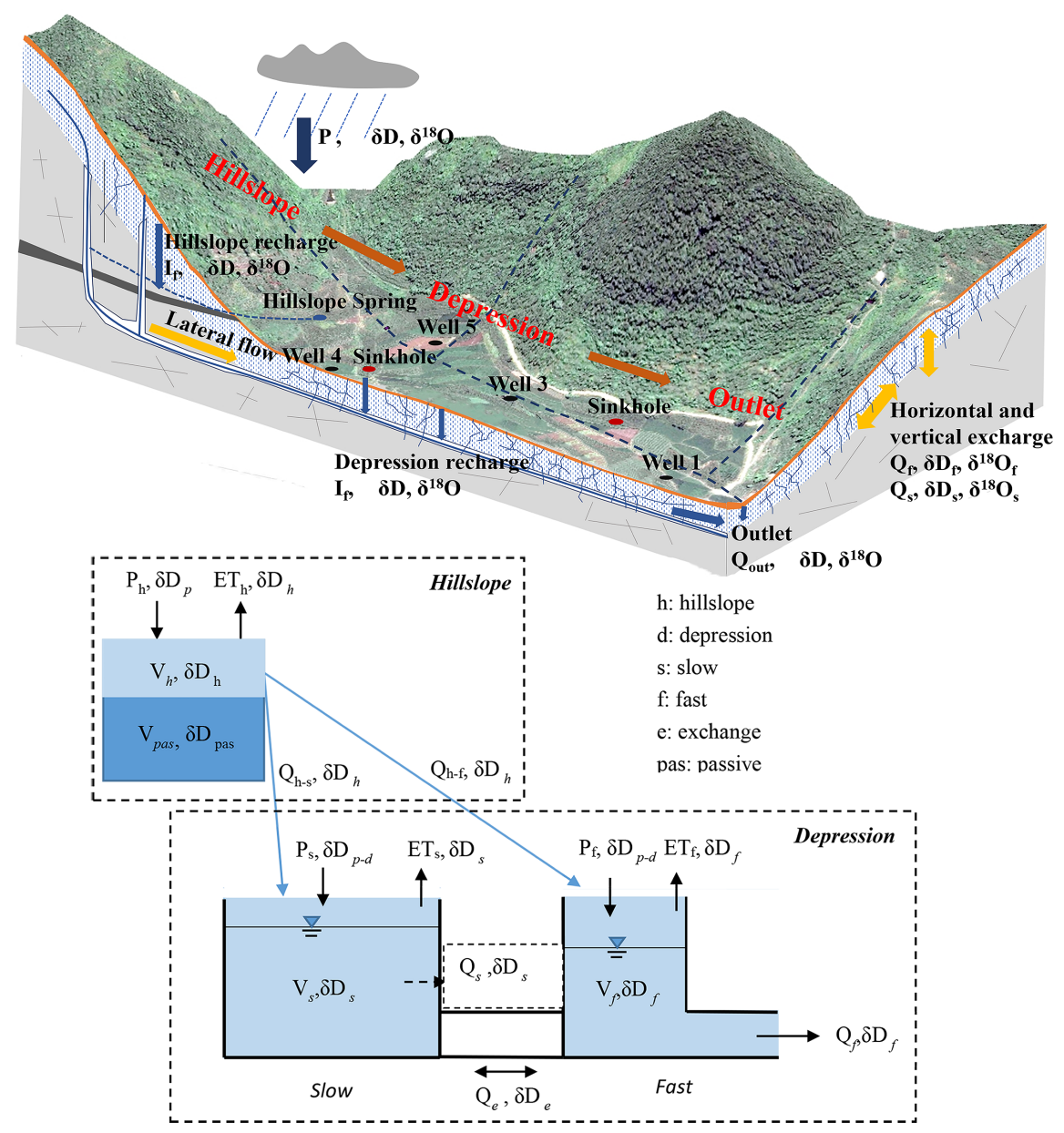




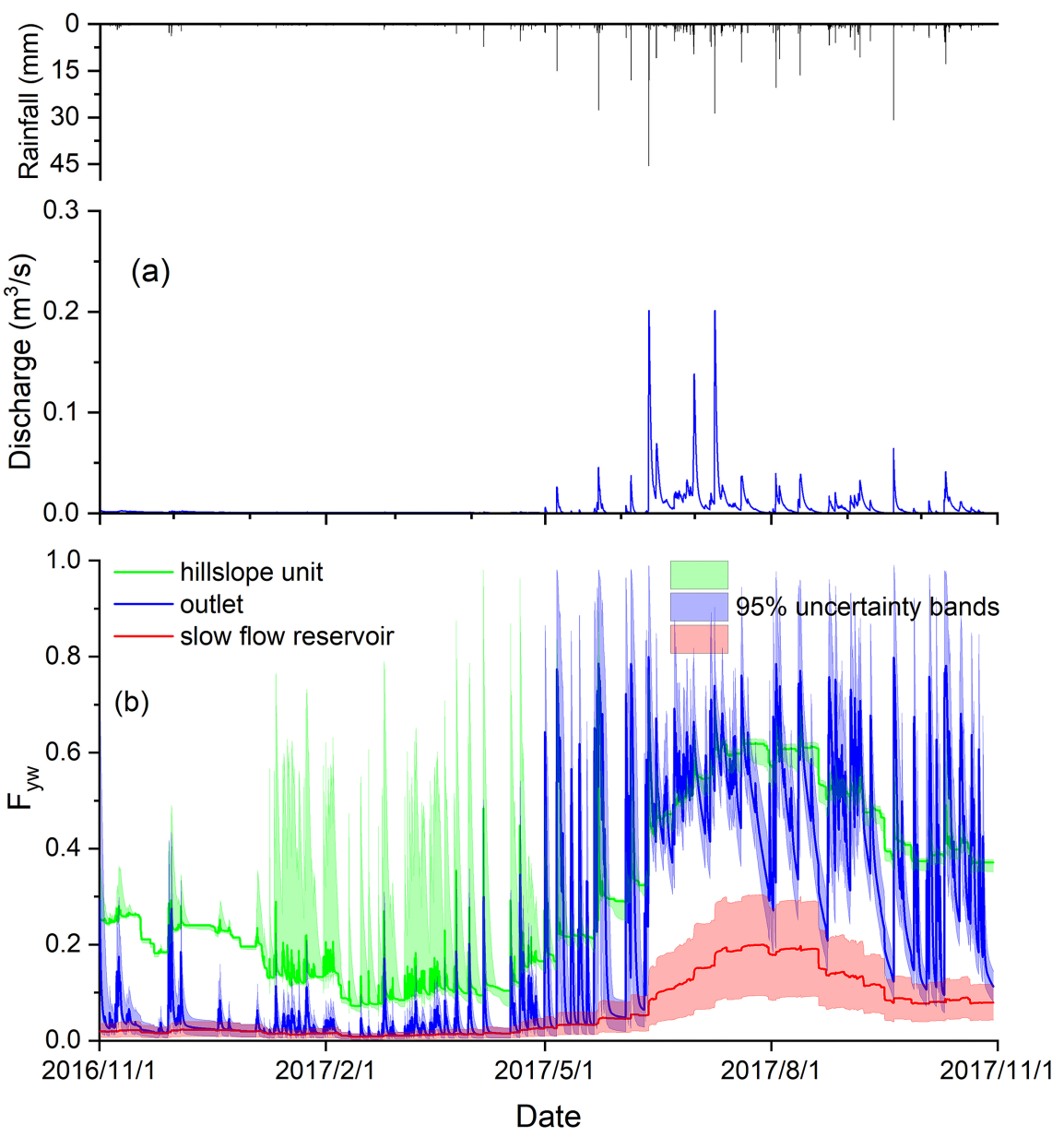




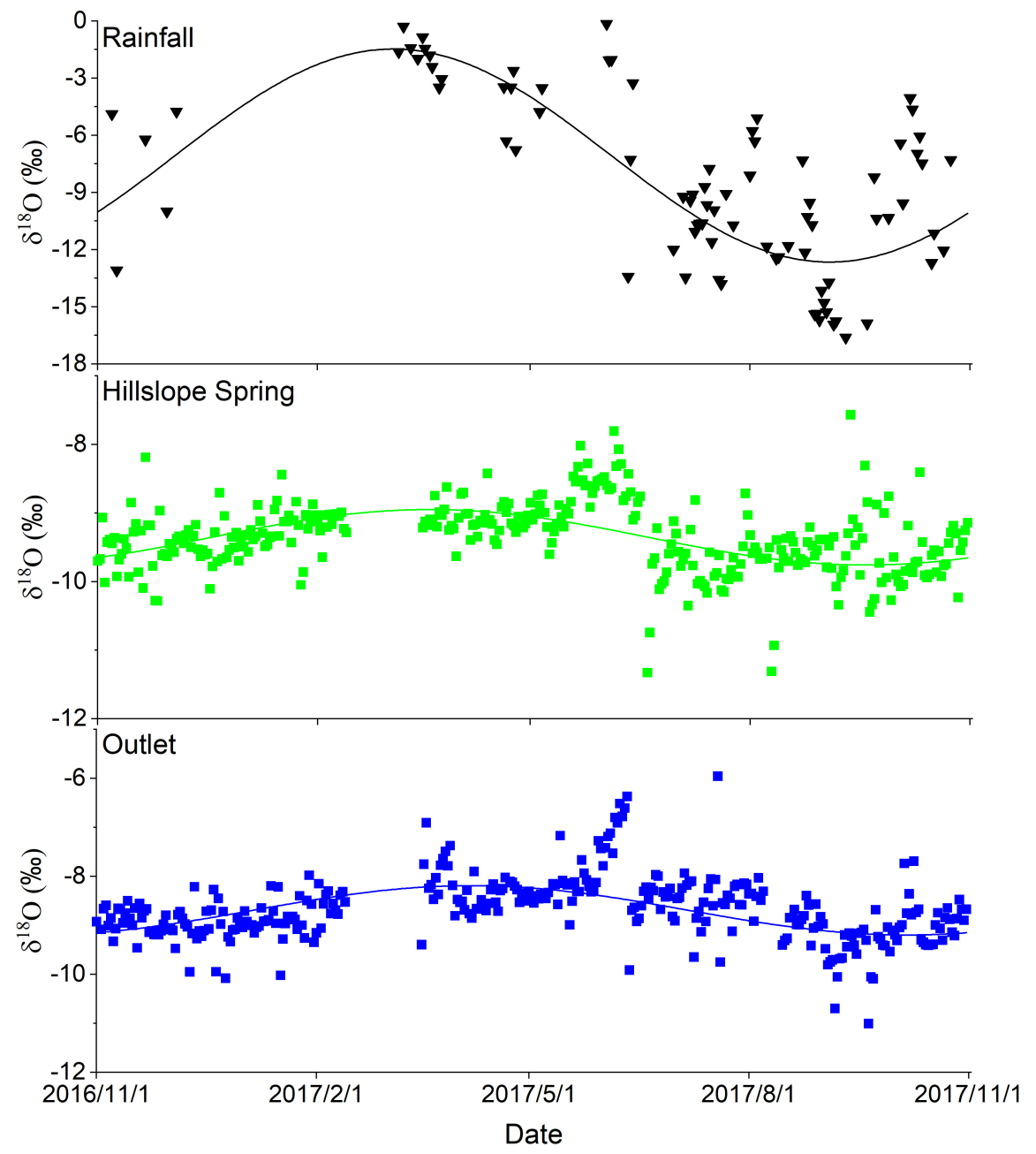



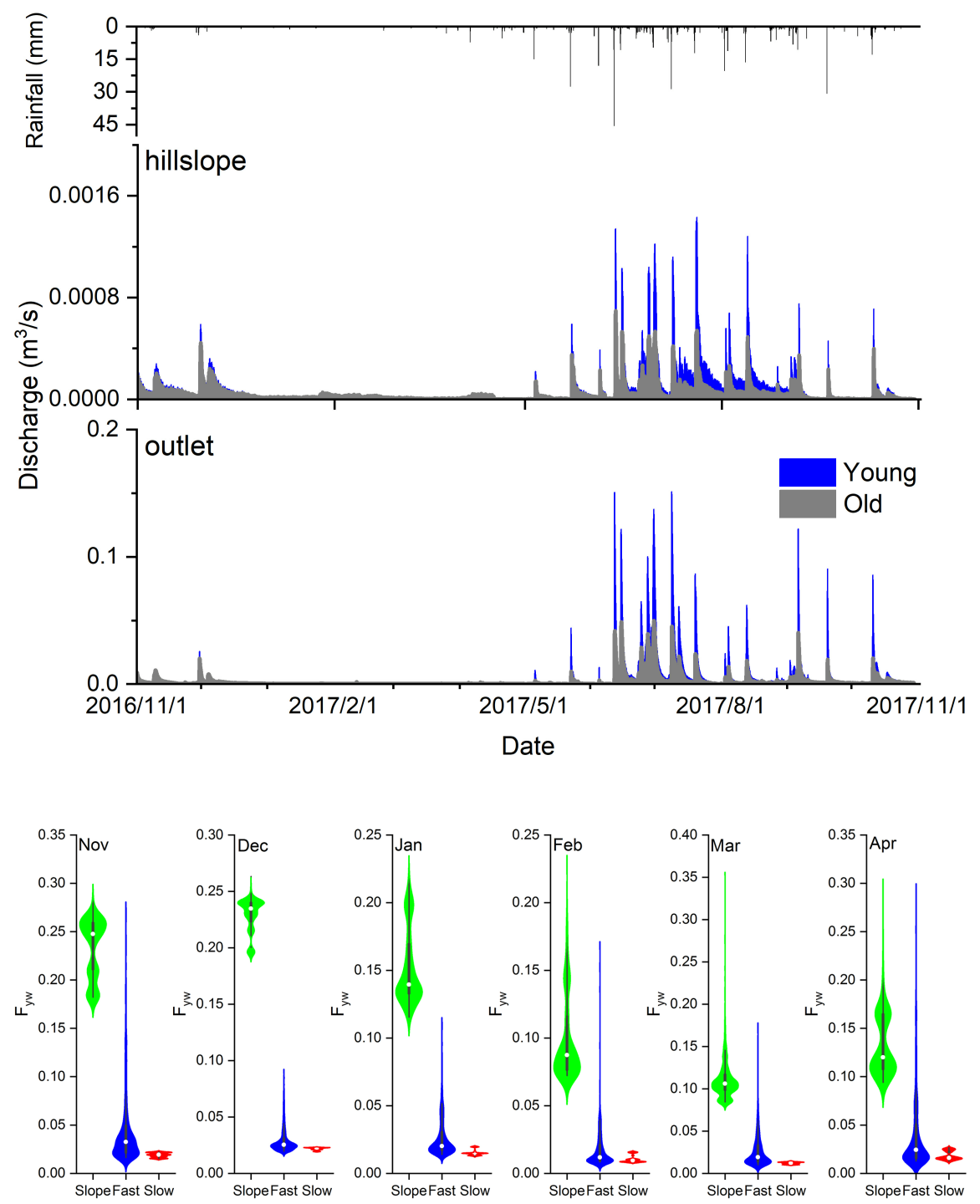

(a)
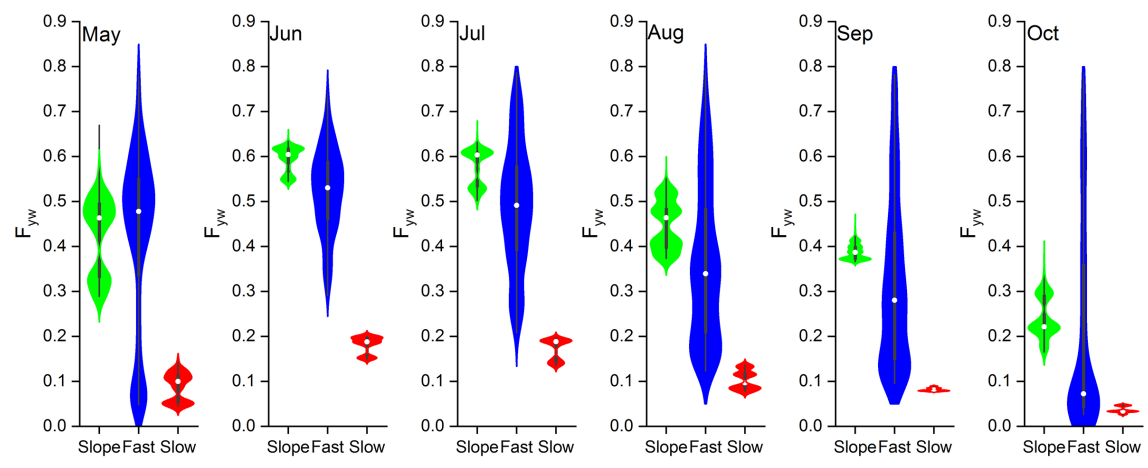

(b) 

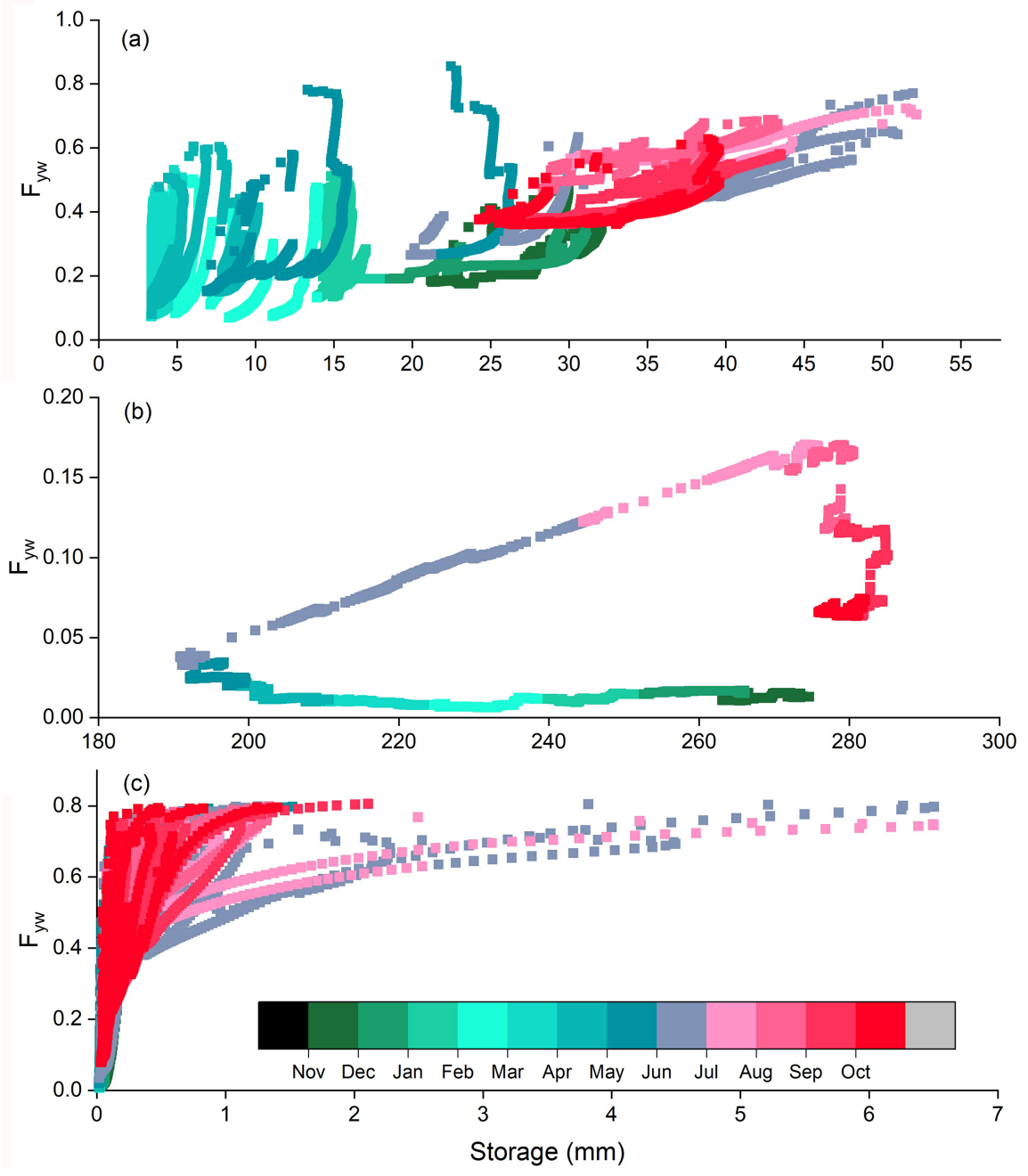


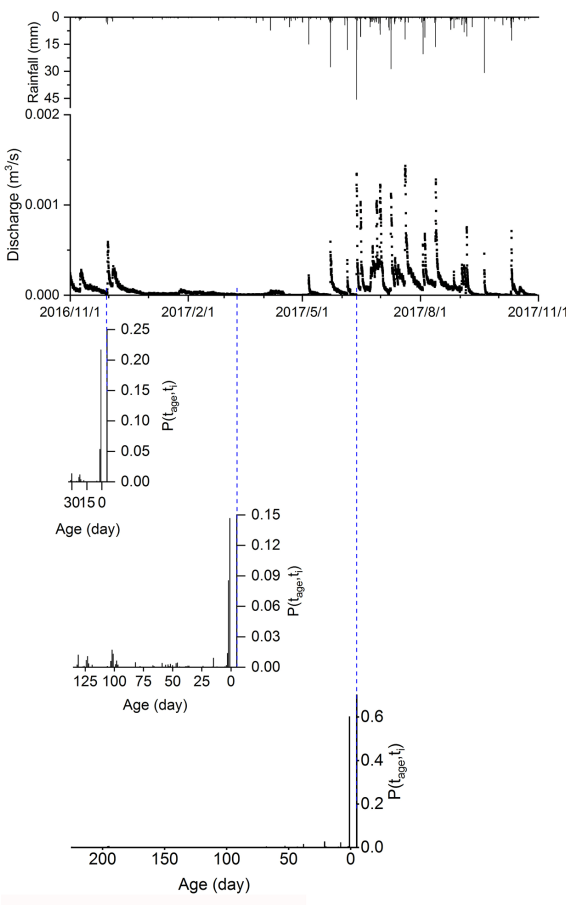

(a)

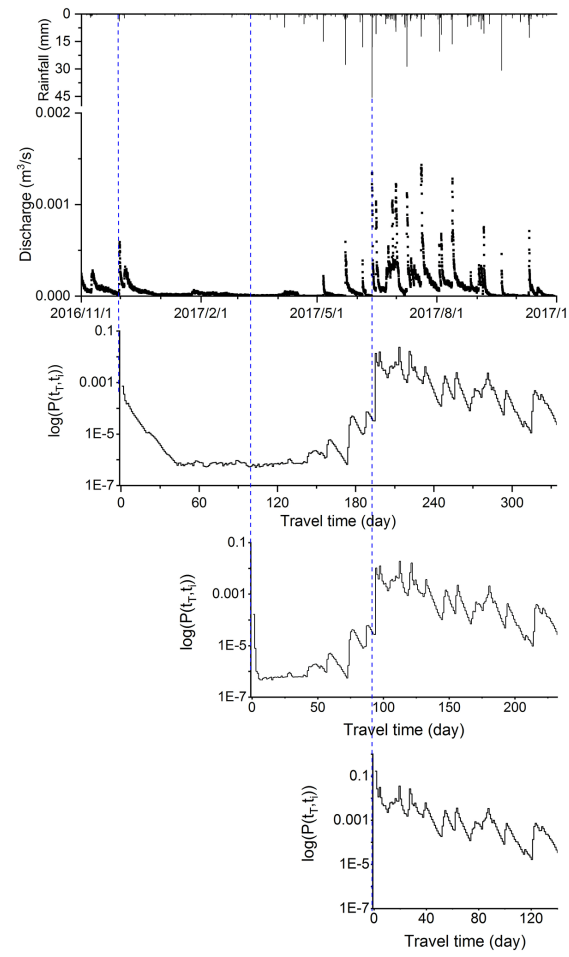

(a)

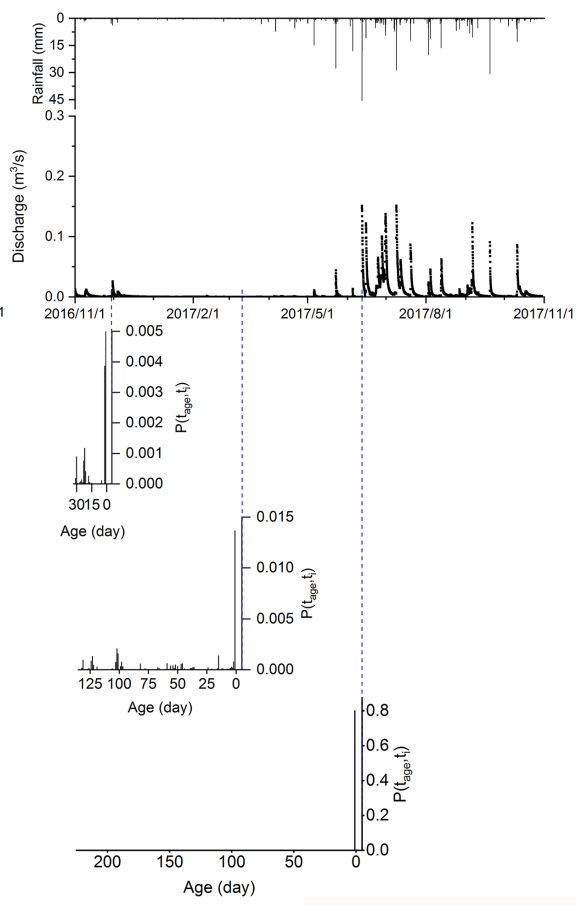

(b)

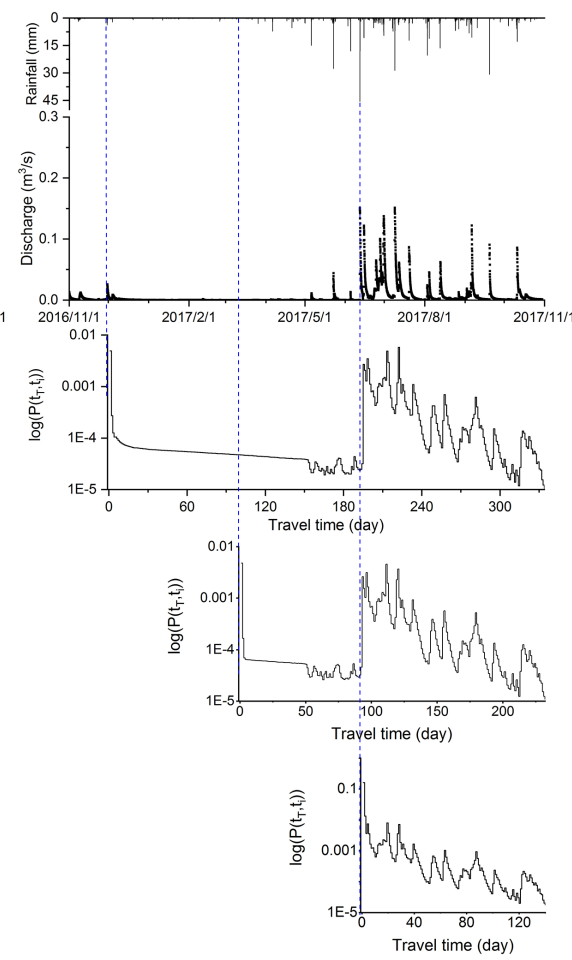

(b) 